\title{
Concurrent Offering of Online and Face-to-Face Courses: Synergies and Challenges
}

\section{Dr. Howard N. Shapiro, Iowa State University}

Dr. Shapiro is a professor emeritus of mechanical engineering at Iowa State University. He received his $\mathrm{BS}$ in mathematics, and his MS and $\mathrm{PhD}$ in mechanical engineering from the Ohio State University and served as a faculty member and administrator at Iowa State for 30 years. In 2005 he became associate vice president and professor at Wayne State university in Detroit, Michigan where he served until 2012. $\mathrm{He}$ is now back at Iowa State teaching in mechanical engineering.

Dr. Shapiro's technical research is in energy efficiency, thermodynamics, refrigeration and energy policy. He has also published and presented heavily in pedagogical subjects, including active learning and learning communities. He is co-author of Fundamentals of Engineering Thermodynamics with Michael Moran, Daisie Boettner, and Margaret Bailey, a recognized leader in thermodynamics education world wide for over 30 years.

\section{Dr. Gloria Starns, Iowa State University}




\title{
Concurrent Offering of Online and Face-to-Face Courses: Synergies and Challenges
}

\author{
Howard N. Shapiro \\ Gloria K, Starns \\ Iowa State University
}

\begin{abstract}
With the advent of Master of Engineering degree programs, departments of mechanical engineering have began offering online sections of master's level courses concurrently with the face-to-face, on-campus sections. This creates significant opportunities and challenges. In this paper, the authors explore these issues through case studies that document their experience with teaching concurrent sections of courses at both the undergraduate and graduate levels. The authors discuss synergies, such as the opportunity for traditional full-time students to interact with off-campus students who mostly are part-time and employed in engineering positions, ways in which online teaching can inform face-to-face teaching, and opportunities to compare the assessment of student learning for online and face-to-face instruction. Some of the challenges include finding ways to engage the online students in similar fashion to the face-to-face students and managing faculty workload if both sections are considered a single assignment. The authors conclude the paper with lessons learned and recommendations for how this type of offering can be made most effective.
\end{abstract}

\section{Introduction}

Effective teaching involves using highly efficacious pedagogy that leads to desired student learning outcomes. These pedagogical principles that have been developed through decades of research are based on how people learn and are not unique to traditional face-to-face instruction. Effective teaching, both face-to-face and on line, requires that the teacher is knowledgeable about best practice and is skilled in delivery. As noted by Watwood, et.al. [1], the advent of online instruction is "serving to disrupt teaching as we previously knew it." This provides unique opportunities for faculty to learn about effective teaching and provides a new context for applying this learning. It also provides significant challenges as many faculty must learn about pedagogy as well as the technological tools available for both online and face-to-face instruction.

In this paper, we discuss both the opportunities and the challenges through two case studies. The courses described were offered concurrently as face-to-face and online sections of the same course. Every attempt was made to use effective pedagogy in each setting that involved engaged learning, on-going formative and summative assessment, and significant interaction among students and between the students and the instructor. We used Chikering and Ehrmann's "Implementing the Seven Principles: Technology as Lever" [2] and "Seven Principles for Good Practice in Undergraduate Education (Chickering and Gamson[3]) as guides. In each course, we attempted to use best practice as laid out in these landmark works: 
1. Encourage contact between students and faculty.

2. Develop reciprocity and cooperation among students.

3. Use active learning techniques.

4. Give prompt feedback.

5. Emphasize time on task.

6. Communicate high expectations.

7. Respect diverse talents and ways of learning.

Traditional face-to-face instruction provides on-going opportunities to structure the learning environment in class in ways that incorporate these best practices. Cooperative learning strategies (See [4]) and classroom assessment (See [5], [6]) are well-established pedagogies that we have both used for years. Teaching online and face-to-face concurrently in the same course provided us with opportunities to incorporate these effective teaching methods into our online classes and to make continuous comparisons of student behavior and student success between the distance and on-campus student groups. It also provided us with the opportunity to learn about and to incorporate effective online learning practice into our face-to-face instruction. Through the following case studies we attempt to chronicle our experiences and to look for lessons that can be instructive to other faculty and that can guide our future endeavors. We respectfully acknowledge that others with considerable experience in online teaching have established recommended best practices; those practices may be better supported and/or refined by any insights gleaned through our case studies. An example of best practices for online instruction [6] follows.

1. "Show Up and Teach". This first practice is intended to remind online faculty that their first responsibility is teaching and consequently they must remain active in the course; the need for sound pedagogy and attention to delivery is no less important than when teaching face-to-face.

2. "Practice Proactive Course Management Strategies". Monitoring student progress, assignment submissions, and identification of students not keeping pace with the course are identified as examples of proactive course management by the instructor.

3. "Establish Patterns of Course Activities". This practice, Ragan notes, benefits both the instructor and student. Having established patterns of activities, students come to understand that responses to questions from the instructor for example will occur within a certain timeframe. Patterns in assignments and submission dates soon become evident so students can plan and dedicate the time to a task accordingly.

4. "Plan for the Unplanned". Short and long term communication strategies should be thought through in the event that the course is interrupted by extenuating or unforeseen circumstances and the strategies should be made clear to students.

5. "Response Requested and Expected". Students should be made aware that responses from the instructor will be provided within a "reasonable" time period. Class size, content domain, and course duration, among other factors, impact the meaning of "reasonable." Generally, a response time between 24 and 72 hours is thought to be reasonable.

6. "Think Before Your Write". Online students do not have the advantage of seeing facial expressions, or hearing voice pitch and tone, when reading corrective or instructive comments from an instructor. This fact needs to be carefully considered when returning feedback to students using written comments. Students should likewise be reminded to review their comments before sending them to the instructor or other students. 
7. "Help Maintain Forward Progress". Clearly communicate assessment strategies to students and return graded assignments and exams within five days of their submission.

8. "Safe and Secure". It is important for both the student and instructor to use resources that ensure communications are going to be sent and received by the intended parties.

Institutional resources and learning management systems should be used as opposed to email accounts and other tools that are not under the auspices of the institution.

9. "Quality Counts". Confusing instructions on assignments, broken links, typographical errors, errors on slides, and anything that would compromise the integrity of the course should be addressed as soon as is possible.

10. "Click on My Connection". Instructors need to be able to comfortably and effectively use the technology made available to deliver content, provide feedback, and communicate with students. Adequate system configurations are essential to ensure a quality experience for both students and instructors.

Case Study I - Undergraduate Machine Design Course

A junior-level undergraduate machine design course was offered in a synchronous format during a six week period in the summer of 2013. Thirty-three students completed the course, 6 face-to-face students and 27 online students. All students were traditional full time students majoring in mechanical engineering. Table 1 indicates the final grade distribution of the class.

Table 1: Case Study I: Grade Distribution - On-campus and On-line

\begin{tabular}{|l|l|l|}
\hline Grade & On-campus $(\mathrm{N}=6)$ & Online $(\mathrm{N}=27)$ \\
\hline A to A- & $6(100 \%)$ & $3(11 \%)$ \\
\hline B+ to B- & 0 & $7(36 \%)$ \\
\hline C+ to C- & 0 & $10(37 \%)$ \\
\hline D+ to D- & 0 & $2(8 \%)$ \\
\hline F & 0 & $5(18 \%)$ \\
\hline
\end{tabular}

Attendance of the face-to-face students was consistently high and engagement of students was above that typically observed in on-campus classes. The face-to-face students adopted a strategy of working independently and then met prior to the collection of assignments to compare answers and work through their differences. This policy and manner of collaboration was suggested to all students enrolled in the class. To ensure that off-campus students were able to collaborate with one another, a discussion board and utility called Piazza was set up for use by the entire class. Students could ask any questions online that they felt were necessary to overcome conceptual misunderstandings, and the board was monitored three times daily by the instructor to endorse and/or correct student responses. Students were assigned to groups and each group had access to its own discussion board as well as to the discussion board for the entire class.

Interestingly, students for the most part tended to be satisfied with discussion and answers from within their own groups and rarely asked questions to a broader audience of students. Given the fact that students could post anonymously, this apparent reluctance to post to the entire class may reflect that students did not want to divulge their failure to watch the video lecture related to the 
material under discussion. Relevant data from the online support office would be necessary to substantiate the merit of the supposition that distance education students were unable to keep pace with the course.

Online office hours were scheduled for one hour in the evenings on three subsequent weekdays. The same students attended online office hours consistently. The reasons for this are varied, but several students indicated that they had to work in the evenings. Typically, at least one student from each student group regularly signed on for office hours. While the motive for having a single member from the group attend office hours may have been to relay information to those students unable to attend office hours, the students representing the group outperformed those students in the group who did not attend office hours. Since office hours were recorded for students unable to attend during the assigned times, those students may have elected not to watch the office hour recordings and rely solely on the communication of the group member who did attend, or they were unable to watch recorded office hours. For those student groups where at least no member attended office hours regularly, they consistently underperformed on assignments and in one case all four group members failed the class.

Group work for online students spanned the spectrum in terms of the quality of work. The fact that students were in groups did not figure as prominently in their performance as the fact that some groups did not engaged in the discussion and office hours. Online students, particularly in a summer term, may be more likely to fall victim to the belief that they will be able to watch several video lectures in one or two sittings and be capable of "catching-up" or learning what they need to learn just in time for the collection of an assignment. Students were cautioned at the start of the class that the accelerated pace of the summer course made it likely that falling behind, whether they were enrolled on campus or online, would likely result in a poor or failing grade.

As grades in the course were close to becoming final, those online students who were going to fail the course or finish with poor grades began to reveal the dynamics of poorly functioning groups. Every student in the course was given the option of working independently and only one online student chose to do so from the outset; that student passed the course with a C-. Online students may be more likely to believe that one successful group member will be able to "save" the group. Online student groups that performed well (B- or higher) also had multiple members in the group who attended on-line office hours regularly.

The workload for the course included two take-home exams, five homework assignments, and a final project. Given that the course spanned a 6 week period, significant effort was required by the students in order to submit assignments by their due dates. Considerable latitude was given on the exams and homework assignments; collaboration was allowed within and across groups. Students were allowed and encouraged to post questions to other students and/or the instructor when they were unable to determine a consistent answer to a problem or to apply concepts. Of the eight teams in the class, four distance education teams consistently capitalized on the opportunity to learn through collaboration or reach out for assistance. The remaining distance education teams rarely posted for any reason and the highest grade earned by any single member of those teams was a C + . The average final grade for students on teams that did not post was $66.3 \%$, or a letter grade of D. The face-to-face students posted primarily for the purpose of answering questions for other students or for clarifying questions on assignments. 
Much as was the case for students, considerable effort was required on behalf of the instructor to deliver content on schedule and as effectively as possible. Several hours beyond that of office hours and class time were required to monitor assignment submission, write rubrics that would probe the ability of students to apply concepts correctly, and identify areas of concern in student understanding. Addressing these concerns were particularly challenging since the duration of the course was short. The fact that students from other institutions (at least 3 the author is aware of) were enrolled complicated the issue of addressing concerns, since preparation of those students was not as well known to the instructor as that of students from the instructor's home institution. All students enrolled in the course met the necessary pre-requisites. Delivery of content, assessment, and remediation proved consistently more challenging and time consuming because the course was on line and asynchronous.

Case Study II - Graduate engineering thermodynamics course

This case study involves a three-credit master-level graduate course in advanced engineering thermodynamics. The pre-requisite is undergraduate engineering thermodynamics. Traditionally, the course has been offered as a fundamental course for masters students in mechanical engineering who major in thermal science areas, and has been an elective for mechanical systems majors and others in mechanical engineering. The course is also open to graduate students in other engineering disciplines. The course is open to highly qualified engineering seniors as an elective and typically a small number of undergraduate students elect the course as well. The oncampus version of the course has been taught for many years, with two meetings a week for a 15week semester. Beginning about five years ago, the college began offering a master of engineering degree that is not specialized in any particular engineering discipline. At that time, all non-laboratory master's courses in the college were required to include online sections that have been taught concurrently with the face-to-face sections. Faculty members teach both sections as one course assignment.

The advanced engineering thermodynamics course had an initial enrollment of eight students at a distance who were pursuing their master of engineering degrees while employed full time and twenty-eight on-campus students, most of whom were mechanical engineering graduate students. Four undergraduates and several master of engineering students were enrolled in the face-to-face section. About two-thirds of the on-campus students had completed at least one semester of undergraduate engineering thermodynamics. The remainder, including most of the online students, had studied thermodynamics in physics but not engineering. For many of the master of engineering students, they had not studied thermodynamics for several years and several had not done well in their undergraduate course(s).

The make-up of the student body in the course created an opportunity for traditional graduate students who started their graduate level studies directly upon completion of their undergraduate degrees to interact with students who are currently employed in engineering or related positions. Students were assigned to small groups to facilitate this exchange. The groups worked together in class and students interacted outside of class through the discussion board of the BlackBoard course management system. At the beginning of the semester, each student was asked to provide a video and/or audio introduction; telling who they were, what their current employment or 
activities were, what their preparation was for the course, and what they expected from the experience. This activity was successful in getting the students engaged early in the course and providing information to the instructor to help guide the teaching efforts.

In order to further facilitate engagement of the online students with the instructor and with each other, a synchronous session with audio and video connections was scheduled as a "required" meeting at a time agreed to by all of the students in the online section. The sessions provided opportunities for the distance students to interact regularly with the instructor and with their peers in a format that captured some of the immediacy of the engaged learning possible in face-to-face instruction. The sessions included a question-and-answer activity, some additional lecture if determined necessary by the instructor, and a chance for the instructor to do some assessment regarding student understanding to inform further instruction. This component was a highly successful adjunct to the recorded lectures and assignments that were available to the online students.

The instructor had not previously taught on line, and teaching on line using the course management tools and with the support of a college center for online learning provided an opportunity to learn how those tools could be incorporated into face-to-face instruction as well. The recorded lectures were made available after the face-to-face class session so students would not be able to use the recordings in lieu of attending class. Further, the online interaction tools of BlackBoard were used by the face-to-face students as well to interact with each other and with the instructor outside of class. Traditional office hours were not heavily utilized, as students were able to get their questions answered in a timely way on line.

The concurrent offering of the online and face-to-face sections allowed for some comparisons of student learning between the two groups. Because of the small number of students in the online section, the comparisons provided here are qualitative. The most significant results related to opening up what had been a course primarily for highly-qualified ME majors with significant prerequisite knowledge of engineering thermodynamics to a broad range of students who were less prepared and many of whom were employed full time and had family commitments. Because of the range, a larger percentage of the online students struggled with the material and performed well below expectations for graduate students. A small percentage of students in the face-to-face course who had similar backgrounds also struggled, but because of the face-to-face format and the use of interactive teaching pedagogy in class, they were more successful ultimately than their online counterparts. The weekly synchronous sessions also helped to address this issue, but it was less effective because there was less opportunity for informal individual interaction between the students and the instructor than was possible face to face.

Graduate courses require at least a grade of $\mathrm{C}$ for credit, and grades below a B place a student in a probationary category. The grades given are presented in Table 2. Although the number of students in the online group was small, the high withdraw/failure rate is uncharacteristic of a traditional graduate course. This reinforces that the online students found it more difficult to commit the time and effort required at this level. 
Table 2: Case Study II: Grade Distribution - On-campus, and On-line

\begin{tabular}{|l|l|l|}
\hline Grades & On line $(\mathrm{N}=7)$ & On campus \\
\hline A to A- & $2(28.6 \%)$ & $14(50 \%)$ \\
\hline B+ to B- & $1(14.3 \%)$ & $11(39.3 \%)$ \\
\hline C+ to C- & $2(28.6 \%)$ & $1(3.6 \%)$ \\
\hline Withdrew or fail & $2(28.6 \%)$ & $2(7.1 \%)$ \\
\hline
\end{tabular}

Teaching an online course involves activities such as preparing and recording lectures, answering students questions posted on discussion boards, evaluating assignments, and providing student feedback. As noted, the instructor chose to also offer a synchronous online class session once a week which added an additional preparation and class period. This was considered on load by the college, so the three-credit course was taught as if it were 4.5 credits in terms of class time. This was the choice of the instructor, but it was deemed necessary in order to deliver a higher quality experience for the online students. The face-to-face sessions were recorded and put on line for all students. These were the primary lectures for the online students and required no additional preparation for the instructor. Several supplementary lectures were also recorded and put on line for all students to make up for the lack of preparation of some students. In addition, two supplemental problem assignments of a remedial nature were provided because of the poor preparation of some students. This also was not an added burden due to the concurrent offering because students in both sections needed that extra help. The need for remedial activities, though, reflects the change of admissions standards in order to reach out to a broader range of students. Finally, the online students needed significant individual feedback that required a great deal of instructor time. Much of this sort of feedback could be handled during class for the face-to-face group or before or after class for individuals. Meeting the needs of the online group was a significant additional burden.

The greatest challenge of the concurrent offerings is finding ways to engage the online students in the course. This challenge is inherent in distance learning, but because of the time constraints it also provides special challenges. Online students have the expectation that they can do the work whenever they find time in their schedules. However, in a graduate course that has continual lectures, assignments, and learning expectations that build on one another, the students must make a significant commitment to keeping up with the pace of the course. This is less of an issue with traditional on-campus graduate students engaged in research and who have traditional assistantship support. But those students were a minority in the course described here, which is increasingly characteristic of online students and, as noted, on-campus students as well.

Data reports from the course management system indicate that the online students accessed the website primarily on the weekends and at rates that were about twice the average of the oncampus students. The synchronous class session for the online students was held on Wednesdays, but there was no apparent spike in web activity in preparation for the session. As noted, though, the course required continuous attention with two class meetings per week and the associated preparation as well as a significant number of assignments that required on-going effort. Oncampus students were held accountable in class for their continuing efforts, and saw the course load as distributed throughout the week. For the online students, attempting to accomplish all of the course requirements in only one or two days of effort was very challenging. 
Teaching concurrent online and face-to-face sections of the same course as a single course assignment is thus a significant challenge. On balance, it is not like teaching two courses, but it is a significant additional assignment compared to a single section in either format. The instructor in this case is an emeritus professor teaching part time and although the assignment was demanding, the instructor had no other academic responsibilities. For tenure-track faculty, teaching the concurrent sections creates a substantial burden that can encroach on other responsibilities or force the teacher to be less attentive to students than otherwise would be possible.

\section{Lessons learned}

Although we taught the two courses described in the above case studies independently, our experiences were similar. We found that the primary challenges of using effective teaching methods in online courses relate to student engagement. In each case, the distance students were provided with a number of tools for interaction with each other and with the instructor. Those who took best advantage of these opportunities were the most successful. This may seem like an obvious conclusion, but in comparing the face-to-face learning with the online learning it was apparent that the face-to-face students who attended class had a more effective educational experience and that instructor was better able to intervene with students who were having difficulty.

The use of web-based tools enhanced the face-to-face classroom experience in both cases. With online tools for interaction, students were better able to get help in a timely way and to provide their colleagues with assistance. This enhanced the learning of the students who had questions, and it helped the students who provided assistance with the opportunity to formulate their thoughts and to express themselves in ways that enhanced their learning as well. Recorded lectures provided additional opportunity for all students to review the material on an as-needed basis. However, in both cases data from the BlackBoard course management indicated that few students took the time to review the lectures in depth.

Student commitment was an issue in both courses. Students in the online section were more likely to view the course as something they could fit in whenever they had the time. The students in the face-to-face class who had several required interactions each week tended to stay on top of their assignments and maintain concentration better than the online students. This was true for both the undergraduate students and for the graduate students. Related to student commitment in the graduate course was the issue of prior preparation of the students. Reaching out to off-campus students, most of whom were working and taking classes part time, is important for access to higher education. However, combining students in this category with traditional on-campus graduate students created a class with broad disparities in level and affected the learning objectives that could be achieved in the course. A similar issue regarding prior preparation was observed with respect to the undergraduate course for students from other institutions who were taking the course remotely.

Teaching online and face-to-face concurrently was found to be a significant increase in load for both instructors. Although there were synergies, the additional preparation and continuous monitoring of student questions required a substantial time commitment compared to teaching in 
either of the two formats exclusively. Both of us were able to make the required time commitment because of our situations. But, this additional commitment is likely to be a concern for tenuretrack faculty, resulting in undue stress and/or the inability to meet student needs. It is recommended that teaching load for such concurrent offerings be adjusted to account properly for the required effort in order for the student experience to be as good as possible.

\section{Summary and Conclusions}

Distance education students should be made aware that the instructor's expectations of them is no different than the expectations for on-campus students; the quantity and quality of work should be comparable for both groups. The pace of the course for distance education students may be affected due to forces that on-campus students are not typically subjected to (full time jobs, child care, etc.) It likewise needs to be made clear that students who engage with the instructor and other students in the course are more likely to earn higher grades. Online, real time office hours appear to be particularly effective in engaging students in discussion and substantive question and answer exchanges. These office hours also afford an opportunity for active learning that is difficult to accomplish in asynchronous modes. Further, the student-faculty interactions provide the teacher with feedback to inform instruction.

The need for timely feedback for distance education students is particularly important due to the fact that the nuances of face-to-face communication that occur in real time are lost [7] with online delivery. Statistics regarding the number of times that students are watching recorded lectures, the average length of time lectures are watched, and when in the semester students are watching recorded videos would be beneficial in determining if intervention by the instructor may be warranted.

Instructors are unable to observe the quality of attention distance education students dedicate to recorded lectures. The perception of students is that the level of attention being devoted to subject matter is greater when they are taking a face-to-face course [8]. It is believed that this perception exists because students are aware of the distractions that are likely to occur while attempting to complete a distance education course [9]. Both authors observed that the distance education students appeared to be far more impacted by distractions than the students enrolled in their faceto-face sections. Since the nature of distractions for online students is, for the most part, unknown to the instructors, it is difficult to eliminate or mitigate them. Distance education students should be advised to establish a protocol for watching pre-recorded lectures, e.g., watch lectures at the same time every evening, secure a place where interruptions are not likely, select an appropriate setting, etc.

\section{Acknowledgements}

The authors would like to acknowledge the professionals in the Engineering OnLine Learning office of Iowa State University for their support and assistance. 
References

1. Chickering, A.W., and S. C. Ehrmann, "Implementing the Seven Principles:Technology as Lever," AAHE Bulletin, October 1966.

2. Chickering, A.W., and Z. F. Gamson, "Seven Principles for Good Practice in Undergraduate Education,” AAHE Bulletin, March 1987.

3. Johnson, D.W., R. T. Johnson, and K. A. Smith, "Active Learning: Cooperation in the College Classroom,” Interaction Book Company, Edina, MN, 1991.

4. M. E. Huba, and J. E. Freed, "Learner-Centered Assessment on College Campuses: shifting the Focus from Teaching to Learning," Allyn and Bacon, 2000.

5. Angelo, T. A. and K. P. Cross, "Classroom Assessment Techniques: A Handbook for College Teachers, $2^{\text {nd }}$ Edition,” Jossey-Bass, Inc., San Fransisco, CA, 1993.

6. Ragan, Lawrence. "Special Report: 10 Principles of Effective Online Teaching: Best Practices in Distance Education”. Faculty Focus. Magna Publications. [January 3, 2014] https://www.facultyfocus.com/account/downloads/?grant_token=78.

7. Cook, D., "Community and Computer-Generated Distance Learning Environments," New Directions for Adult and Continuing Education, no. 67, Fall, 1995, pp. 33-39.

8. Isaacs, E., et al., "A Comparison of Face-to-Face and Distributed Presentations," Proceedings, Conference on Computer Human Interaction (CHI '95), May 1995, Denver, CO, pp. 354-361.

9. Williamson, Christopher, Jennifer Bernhard and Kent Chamberlin. "Perceptions on an InternetBased Synchronous Distance Learning Experience," Journal of Engineering Education, January 2000, pp. 53-61. 